\title{
Two years' experience with denosumab for children with Osteogenesis imperfecta type VI
}

\author{
Heike Hoyer-Kuhn ${ }^{1 *}$, Christian Netzer ${ }^{2}$, Friederike Koerber ${ }^{3}$, Eckhard Schoenau ${ }^{1}$ and Oliver Semler ${ }^{1}$
}

\begin{abstract}
Background: Osteogenesis imperfecta $(\mathrm{OI})$ is a hereditary disease causing reduced bone mass, increased fracture rate, long bone deformities and vertebral compressions. Additional non skeletal findings are caused by impaired collagen function and include hyperlaxity of joints and blue sclera. Most Ol cases are caused by dominant mutations in COL1A1/2 affecting bone formation. During the last years, recessive forms of OI have been identified, mostly affecting posttranslational modification of collagen. In 2011, mutations in SERPINF1 were identified as the molecular cause of Ol type VI, and thereby a novel pathophysiology of the disease was elucidated. The subgroup of patients with $\mathrm{Ol}$ type $\mathrm{VI}$ are affected by an increased bone resorption, leading to the same symptoms as observed in patients with an impaired bone formation. Severely affected children are currently treated with intravenous bisphosphonates regardless of the underlying mutation and pathophysiology. Patients with OI type $\mathrm{VI}$ are known to have a poor response to such a bisphosphonate treatment.
\end{abstract}

Method: Deciphering the genetic cause of Ol type VI in our 4 patients (three children and one adolescent) led to an immediate translational approach in the form of a treatment with the monoclonal RANKL antibody Denosumab (1 $\mathrm{mg} / \mathrm{kg}$ body weight every 12 weeks).

Results: Short-term biochemical response to this treatment was reported previously. We now present the results after 2 years of treatment and demonstrate a long term benefit as well as an increase of bone mineral density, a normalization of vertebral shape, an increase of mobility, and a reduced fracture rate.

Conclusion: This report presents the first two-year data of denosumab treatment in patients with Osteogenesis imperfecta type VI and in Osteogenesis imperfecta in general as an effective and apparently safe treatment option.

Keywords: Osteogenesis imperfecta VI, SERPINF1, RANKL Antibody, Denosumab, Bone mineral density

\section{Introduction}

Osteogenesis imperfecta (OI) is a genetically heterogeneous hereditary disease characterized by reduced bone mass, increased fracture rate, vertebral collapses and deformities of long bones. Non-skeletal findings, e.g., dentinogenesis imperfecta, blue sclera, or hyperlaxity of ligaments, can be associated. Dominant mutations in COL1A1 or COL1A2 that lead to a quantitative or a qualitative defect in collagen type I are the molecular cause in the majority of patients [1]. Severely affected individuals are treated with intravenous bisphosphonates regardless of the underlying genetic cause $[2,3]$.

\footnotetext{
* Correspondence: heike-katharina.hoyer-kuhn@uk-koeln.de 'Children's Hospital, University of Cologne, Kerpenerstr. 62, D-50931 Cologne, Germany

Full list of author information is available at the end of the article
}

Osteogenesis imperfecta type VI (OI VI) is autosomalrecessively inherited and displays an increased amount of non-mineralized osteoid and a poor response to bisphosphonate treatment $[4,5]$. Additional signs are the only discrete findings at birth and the late onset of fractures and deformities. OI VI is caused by mutations in SERPINF1, a gene which is coding for the pigment epithelium-derived factor (PEDF) [6,7]. In patients with bi-allelic truncating mutations in SERPINF1, PEDF is not detectable in the serum [8]. In-vitro and in-vivo models provided evidence that PEDF inhibits osteoclast differentiation and hence bone resorption via osteoprotegerin (OPG) and RANKL [9]. Receptor activator of NF-kB (RANK), the ligand RANKL, and the decoy receptor OPG are pivotal regulators of osteoclast differentiation and function. Denosumab is a monoclonal RANKL-blocking antibody which inhibits 
osteoclast formation and bone degradation and increases bone mass. It has been approved for the treatment of postmenopausal osteoporosis in 2010 and of giant cell tumors of the bone in 2013 [10,11].

We report the first 2-year results of four patients with genetically confirmed OI VI treated with denosumab. Understanding the different pathogenesis had encouraged us to target the RANK/RANKL pathway directly with this RANKL antibody as an individual translational therapeutic approach. Preliminary data of these four patients on biochemical bone turn-over markers in the course of a maximum of three treatment cycles have recently been published by our group [12]. To our knowledge, these new data about a two years' experience are the first about denosumab treatment, side effects and efficacy determined by changes of the areal bone mineral density (aBMD) and vertebral morphometry in children with Osteogenesis imperfecta.

\section{Patient}

The boys were born to three different consanguineous couples and presented with a severe phenotype of OI VI [4]. The clinical findings and clinical courses have been described in the former publication [12]. OI had been diagnosed clinically when the first fractures had occurred. Spine X-rays had revealed multiple vertebral fractures and deformities. A therapy with intravenous bisphosphonates had been started as described [12]. During bisphosphonate therapy treatment response was poor. All children were depending on a wheelchair. In these patients, we had identified the causal SERPINF1 mutations and had discovered the genetic cause of OI VI in the course of a previous research project [6]. Additionally, Osteoprotegerin levels as an osteoclastogenesis inhibitory factor were analyzed in two of these patients and showed reduced values $(3.0 ; 4.0 \mathrm{pmol} / \mathrm{l}$ [normal range $5.7 \pm 0.42 \mathrm{pmol} / \mathrm{l}]$ ).

Informed consent was obtained according to the Declaration of Helsinki and an individual translational therapeutic approach with the RANKL antibody denosumab (Prolia ${ }^{\circ}$, Amgen, Thousand Oaks) was started. Denosumab was injected subcutaneously with a dose of $1 \mathrm{mg}$ per $\mathrm{kg}$ body weight. Oral supplementation with calcium (body weight $\geq 15 \mathrm{~kg}: 1000 \mathrm{mg}$ per day; body weight $\leq 15 \mathrm{~kg}$ : $500 \mathrm{mg}$ per day) was administered for 2 weeks after each injection. Additionally, vitamin D (body weight $\leq 30 \mathrm{~kg}$ : 500 international units per day; body weight $\geq 30 \mathrm{~kg}$ : 1000 international units per day) was prescribed in all patients because they were vitamin $D$ depleted. Initially, treatment intervals were 12 weeks. These intervals were chosen according to the intervals used in adults [13]. After one year of treatment all patients were assigned to shorter intervals (minimum 10week ) based on the recurrence of skeletal pain and on the increase of osteoclastic activity 8 weeks after injection measured by urinary deoxypyridinoline levels/creatinine (DPD) (data not shown).

\section{Methods}

Dual-energy X-ray absorptiometry was performed at the lumbar spine (L2-L4) and for the total body (excluding the head) using a GE Lunar iDXA densitometer (GE Ultraschall $\mathrm{GmbH}$, Solingen, Germany) and Encore software version 13.6. Areal BMD results were transformed to age-specific $\mathrm{z}$-scores using reference data provided by the company [14].

We used urinary deoxypyridinoline/creatinine ratio (DPD/crea) to quantify and monitor the inhibition of bone resorption. Urinary concentrations of DPD were measured with a commercially available chemiluminescence assay (Pyrilinks ${ }^{\circ}$-D, Siemens Medical Solutions Diagnostics). The DPD/crea ratio was compared to ageand sex- matched reference data, as published by our laboratory [15]. Due to a change of the analytic procedures we had to analyze the later samples with HighPerformance-Liquid-Chromatography with age matched reference data. Osteocalcin (Enzyme-immuno-Assay, reference ranges 10-100 ng/ml), Parathyroid hormone (Modular E-Modul, Roche Diagnostics, Germany, reference range $12-72 \mathrm{ng} / \mathrm{l}), 25-\mathrm{OH}$ Vitamin D Modular E-Modul, Roche Diagnostics, Germany, reference range 30-70 $\mu \mathrm{g} / \mathrm{l}$ ) and total serum Calcium (Modular P-Modul, Roche Diagnostics, Germany, reference range 2.2-2.65 mmol/l) were measured in the serum by our university central laboratory.

Lateral $x$-rays of the spine were taken routinely. Spine morphometry was evaluated based on the semiquantitative score described by Koerber et al. assessing vertebral compression and deformity [16]. They were evaluated by the same radiologist. Additionally, calculation of the projected vertebral area of the lumbar vertebrae (L2-L4) was performed as described recently [17].

Mobility was assessed using the Gross Motor Function Measure (GMFM66) [18] and the Brief Assessment of Motor Function (BAMF) [19].

\section{Results}

After two years of treatment all 4 patients were in a stable clinical condition. There was no treatment interruption based on unexpected side effects. Especially no signs of allergic reactions or clinical significant hypocalcemia have been reported. Patients 3 and 4 reported in the previous publication intermittently went back to their mother country for nearly one year. Therefore results of mobility and data of one year follow up were presented in detail only for patient 1 and 2 . 


\section{Clinical data}

A synopsis of the clinical data and clinical course is given in Table 1. In three children, body length increased during denosumab treatment. One patient reached his final height before starting denosumab. Two patients suffered two fractures during the follow-up period due to mild traumata.

\section{Areal bone mineral density}

Areal bone mineral density was assessed once a year. In all subjects, a continuous increase of aBMD was seen after one and two years of denosumab treatment. Agematched z-scores and absolute values of patient 1 and 2 are presented graphically in Figure 1 . In patient 3 and 4 aBMD (total body less head) changed from $0.373 \mathrm{~g} / \mathrm{cm}^{2}$ (z-score -2.9) to $0.407 \mathrm{~g} / \mathrm{cm}^{2}(\mathrm{z}$-score -2.9$)$ and from $0.59 \mathrm{~g} / \mathrm{cm}^{2}$ (z-score -2.8 ) to $0.633 \mathrm{~g} / \mathrm{cm}^{2}$ (z-score -2.6 ), respectively at the only follow up visit after two years.

\section{Desoxypyridinoline level}

A decrease of DPD excretion after denosumab injections into the reference range could be observed repeatedly. Data are presented exemplarily in Table 2 [15].

\section{Spine morphology}

Changes of spine morphology of patient 1 and 2 during denosumab treatment in the lateral spine $\mathrm{x}$-rays are presented in Figure 1. The vertebrae showed a re-shape phenomenon in both patients. A standardized assessment of the spine morphology revealed a stabilization and/or improvement in both children. The score levels are presented in Figure 1. Additionally, morphometric parameters are presented in Figure 1, showing an increase of the complete lumbar vertebral area of L2-L4.

\section{Mobility}

The GMFM ranks showed stable results in both patients 1 and 2. GMFM 66 scores are presented in Table 1. The patients were not able to stand, walk, or jump, but at least mobility scores did not decrease further.

BAMF was additionally assessed every year and showed a slight increase after two years of denosumab treatment in all patients (Table 1).

\section{Safety}

No severe side effects were reported by our 4 patients. All injections were well tolerated without any changes in vital signs. Serum calcium concentrations decreased repeatedly, and serum parathyroid hormone levels increased slightly (Table 3 ). There was no secondary hyperparathyreoidism observed over the whole period of two years. The slight hypocalcaemia after each injection could be compensated by oral calcium supplementation (lowest ionisized serum calcium level was $0.96 \mathrm{mmol} / \mathrm{l}$, lowest total serum calcium level $1.97 \mathrm{mmol} / \mathrm{l})$. Osteocalcin levels as a marker for bone formation stayed in the age related normal range in all patients (Table 3). No increased rate of infections was observed. Two patients suffered two fractures during the follow-up period due to mild trauma. The 3

Table 1 Clinical characteristics at the start and during denosumab treatment

\begin{tabular}{|c|c|c|c|c|}
\hline Findings & Patient 1 & Patient 2 & Patient 3 & Patient 4 \\
\hline Mutation in SERPINF1 & c.324_325dupCT & C. $1132 \mathrm{C}>\mathrm{T}$ & c. $696 C>G$ & c. $696 C>G$ \\
\hline Duration of previous bisphosphonate treatment [years] & 8.1 & 5.75 & 3.4 & 3.4 \\
\hline Age at start of denosumab therapy [years] & 9.4 & 6.9 & 5.7 & 18.5 \\
\hline Time since first denosumab injection [years] & 2.4 & 2.1 & 2.0 & 2.0 \\
\hline Number of denosumab treatment cycles [n] & 12 & 10 & 8 & 8 \\
\hline Length $[\mathrm{cm}](\mathrm{SD})$ at start & $109(-4.0)$ & $102(-3.55)$ & $89(-5.8)$ & $120(-9.9)$ \\
\hline Length $[\mathrm{cm}](\mathrm{SD})$ after two years & $117(-3.7)$ & $107(-4.3)$ & $95(-6.2)$ & $120(-9.9)$ \\
\hline Weight $[\mathrm{kg}] / \mathrm{BMI}\left[\mathrm{kg} / \mathrm{m}^{2}\right]$ at start & $19.7 / 16.6$ & $14.7 / 14.1$ & $10.8 / 13.6$ & $51.4 / 35.7$ \\
\hline Weight $[\mathrm{kg}] / \mathrm{BMI}\left[\mathrm{kg} / \mathrm{m}^{2}\right]$ after two years & $28.2 / 20.6$ & $17.5 / 15.3$ & $11.0 / 12.2$ & $54.0 / 37.5$ \\
\hline BAMF mobility score at start & 3 & 3 & 4 & 2 \\
\hline BAMF mobility score after one year & 3 & 3 & - & - \\
\hline BAMF mobility score after two years & 4 & 4 & 5 & 3 \\
\hline GMFM 66 score at start & 32.31 & 34.84 & - & - \\
\hline GMFM 66 score after one year & 31.78 & 40.20 & - & - \\
\hline GMFM 66 score after two years & 34.37 & 40.67 & - & - \\
\hline Fractures under denosumab treatment [n] & 2 & 2 & 0 & 0 \\
\hline
\end{tabular}




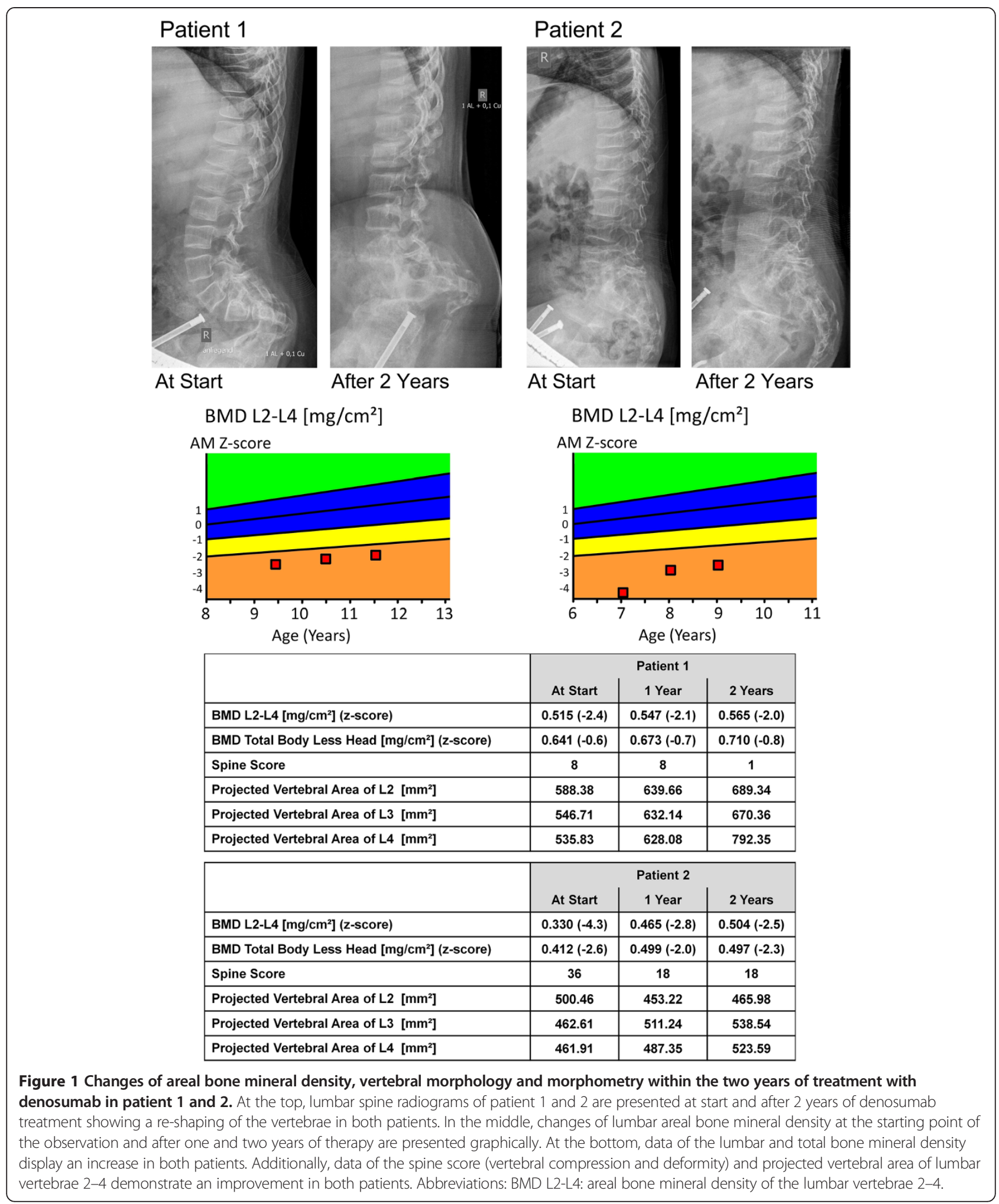

patients which did not reach final height before start of treatment showed an increase of body length during the treatment period of $8 \mathrm{~cm}, 5 \mathrm{~cm}$ and $6 \mathrm{~cm}$, respectively.

\section{Discussion}

\section{Efficacy}

Measurements of urinary DPD showed a suppression of bone resorption after denosumab application, and 
Table 2 Changes of urinary deoxypyridinoline excretion during denosumab treatment

\begin{tabular}{|c|c|c|c|c|}
\hline & \multicolumn{4}{|c|}{ Urinary deoxypyridinoline/creatinine ratio (age related normal range) } \\
\hline & Patient 1 & Patient 2 & Patient 3 & Patient 4 \\
\hline Days after injection & $1^{\text {st }}$ Cycle & $1^{\text {st }}$ Cycle & $1^{\text {st }}$ Cycle & $1^{\text {st }}$ Cycle \\
\hline Day 1 & $44(6.5-26.5 \mathrm{nM} / \mathrm{mM})$ & $32(6.5-26.5 \mathrm{nM} / \mathrm{mM})$ & $82(6.5-26.5 \mathrm{nM} / \mathrm{mM})$ & $41(0.0-17.8 \mathrm{nM} / \mathrm{mM})$ \\
\hline Day 14 & $14(6.5-26.5 \mathrm{nM} / \mathrm{mM})$ & $25(6.5-26.5 \mathrm{nM} / \mathrm{mM})$ & $26(6.5-26.5 \mathrm{nM} / \mathrm{mM})$ & $20(0.0-17.8 \mathrm{nM} / \mathrm{mM})$ \\
\hline \multirow[t]{2}{*}{ Day 28} & $25(6.5-26.5 \mathrm{nM} / \mathrm{mM})$ & $13(6.5-26.5 \mathrm{nM} / \mathrm{mM})$ & $25(6.5-26.5 \mathrm{nM} / \mathrm{mM})$ & $17(0.0-17.8 \mathrm{nM} / \mathrm{mM})$ \\
\hline & $3^{\text {rd }}$ Cycle & $4^{\text {th }}$ Cycle & $8^{\text {th }}$ Cycle & $8^{\text {th }}$ Cycle \\
\hline Day 1 & $48(6.5-26.5 \mathrm{nM} / \mathrm{mM})$ & $78(6.5-26.5 \mathrm{nM} / \mathrm{mM})$ & $620(110-450 \mu \mathrm{g} / \mathrm{g})$ & $83(10-50 \mu \mathrm{g} / \mathrm{g})$ \\
\hline Day 14 & $10(6.5-26.5 \mathrm{nM} / \mathrm{mM})$ & $24(6.5-26.5 \mathrm{nM} / \mathrm{mM})$ & $133(110-450 \mu \mathrm{g} / \mathrm{g})$ & $50(10-50 \mu \mathrm{g} / \mathrm{g})$ \\
\hline \multirow[t]{2}{*}{ Day 28} & $32(6.5-26.5 \mathrm{nM} / \mathrm{mM})$ & $19(6.5-26.5 \mathrm{nM} / \mathrm{mM})$ & $431 *(110-450 \mu \mathrm{g} / \mathrm{g})$ & $23(10-50 \mu \mathrm{g} / \mathrm{g})$ \\
\hline & $7^{\text {th }}$ Cycle & $10^{\text {th }}$ Cycle & - & - \\
\hline Day 1 & $42(6.5-26.5 \mathrm{nM} / \mathrm{mM})$ & $477(110-450 \mu \mathrm{g} / \mathrm{g})$ & - & - \\
\hline Day 14 & $28(6.5-26.5 \mathrm{nM} / \mathrm{mM})$ & $110(110-450 \mu \mathrm{g} / \mathrm{g})$ & - & - \\
\hline Day 28 & $19(6.5-26.5 \mathrm{nM} / \mathrm{mM})$ & $197(110-450 \mu \mathrm{g} / \mathrm{g})$ & - & - \\
\hline
\end{tabular}

Changes of urinary deoxypyridinoline levels (urinary deoxypyridinoline/creatinine ratio) presented exemplarily for different treatment cycles in all patients. Based on a change of the method reference ranges differed over the period and for clarity every reference range (as provided by the laboratories) are shown after every measured DPD level. The results of the first cycle and of previous bisphosphonate therapy have already been described in part [12].

$* \rightarrow$ Value 3 days after elective surgery of right femur due to dislocation of intramedullary rod.

consequently, an increase of areal bone mineral density was observed in all patients. These are the major findings which underline efficacy of the denosumab treatment (Figure 1; Tables 2 and 3). In general, the clinical course of all patients improved as reported by the families. It is known that bisphosphonates are not as effective in children with OI VI as in children with other types of OI [5]. Therefore these results are interesting especially because both agents are "antiresorptive agents". It might be argued that the large amount of osteoid which is characteristic for OI VI is responsible for a reduced efficacy of bisphosphonates. Bisphosphonates bind on the hydroxylapatites on the bone surface. Osteoid as the unmineralized compartment of the bone could not be bound by bisphosphonates and therefore the induction of osteoclastic apoptosis by bisphosphonates might not be as effective in OI VI as in other types of OI [5]. Denosumab as a RANKL antibody acts independently of the mineralization status of the bone, a fact that raises the possibility that this antiresorptive agent may be more effective in reducing osteoclast formation, maturation and bone resorption in patients with OI VI. Further trials are needed to compare the effect of a therapy with bisphosphonates and denosumab in children with OI.

A detailed analysis of the morphometric parameters of the radiographs taken from the lateral spine showed an improvement of the shape of the vertebrae which is essential for stability. This effect was shown by bisphosphonate treatment in children with typical OI (mutations in COL1A1/A2) but was not reported in OI VI $[5,17]$.

The four patients with OI VI were severely affected. In this context, the clinical course during denosumab treatment was satisfying, as fracture rates decreased in all patients and mobility scores showed a slight increase.
Additionally, patients reported reduced bone pain in the weeks following each denosumab injections, and a recurrence of bone pain at the end of each treatment cycle.

Based on our data no final conclusions about duration of treatment or frequency of injections can be drawn. It could be speculated that the treatment should be continued till the end of growth, similar to the currently used regime for bisphosphonates. Bone turnover is especially high during childhood and adolescents, and a strong effect of an antiresorptive treatment can be expected. A treatment until the end of puberty might also decrease the risk of a rebound effect after the end of therapy. However, these questions have to be answered in further trials.

\section{Safety}

No severe side effects were observed. The observed mild side effects were those cited in the investigators brochure. The drop of serum calcium, a phenomenon which can be considered as an indicator for the decreased ability of osteoclasts to resorb bone and to release calcium, was easy to correct by oral supplementation and vitamin D supplementation. A decrease in calcium has also been reported in osteoporotic adults treated with denosumab [20] and is a common side effect of antiresorptive agents. This side effect was even used to treat hypercalcemia in 2 children after stem cell transplantation in osteopetrosis [21]. Intravenous calcium substitution as it was described in a child with juvenile Paget disease was not needed [22]. At the end of each treatment cycle no hypercalcemia as it was reported for other patients $[22,23]$ was observed in our patients. The previous bisphosphonate treatment may have attenuated this 
Table 3 Bone metabolism markers in patient 1-4 in the last denosumab treatment cylce

\begin{tabular}{|c|c|c|c|c|c|c|c|c|c|c|}
\hline \multirow[b]{2}{*}{ Parameter/day after denosumab injection } & \multirow{2}{*}{$\begin{array}{l}\text { Patient } 1 \\
\text { Day } 0\end{array}$} & \multicolumn{3}{|l|}{ Patient 2} & \multicolumn{3}{|c|}{ Patient 3} & \multicolumn{3}{|c|}{ Patient 4} \\
\hline & & Day 0 & 14 & 28 & Day 0 & 14 & 28 & Day 0 & 14 & 28 \\
\hline $\begin{array}{l}\text { Osteocalcin (age adjusted normal range) } \\
\text { [ng/ml] }\end{array}$ & $24(10.0-100.0)$ & $45(10.0-50.0)$ & & & $40(10 . c$ & & & $21(9.6$ & & \\
\hline Parathyroid hormone (12-72 ng/l) & 16 & 7 & 40 & 31 & 14 & 22 & 19 & 48 & 45 & 46 \\
\hline Calcium (2.2-2.65 mmol/l) & 2.48 & 2.48 & 2.14 & 2.35 & 2.39 & 2.25 & 2.35 & 2.37 & 2.31 & 2.46 \\
\hline 25-OH Vitamin D $(30-70 \mu \mathrm{g} / \mathrm{l})$ & 19 & 15.4 & 23.2 & 26.7 & 8.2 & 8.8 & 4.3 & 12.2 & 10.8 & 8.1 \\
\hline
\end{tabular}

Desoxypyridinoline/creatinine (age adjusted $600(110-450) \quad 477(110-450) \quad 110(110-450) \quad 197\left(110-450 \quad 620(110-450) \quad 133(110-450) \quad 431^{*}(110-450) \quad 83(10-50) \quad 50(10-50) \quad 23(10-50)\right.$ normal range) $[\mu \mathrm{g} / \mathrm{g}]$

${ }^{*} \rightarrow$ Urin collected 3 days after elective surgery of right femur due to dislocation of intramedullary rod. 
rebound effect. However, the patients reported in the literature also received bisphosphonates prior to denosumab. Another reason for the absence of hypercalcemia in our patients might be the supplementation regime for calcium, which we administered for only 2 weeks after the denosumab injections, compared to a continuous treatment in the patient with paget disease. Additionally, the differing pathophysiology in patients with OI type VI may have influenced the effect of denosumab on serum calcium levels.

In our patients no increase of fractures, bone pain and infections has been reported by the patients and their parents. No growth arrest was observed. The observed height velocity was reduced in comparison with healthy children but was not reduced in comparison to the prior period under bisphosphonate treatment.

After two years of application, the benefits seem to overweigh the risks of treatment.

In the long term, denosumab might offer an advantage in different disorders with increased bone resorption because it completely degrades within 3-6 months after an injection of $1 \mathrm{mg} / \mathrm{kg}$ body weight [24]. Bisphosphonates are stored in the bone persistently, a fact which has led to an ongoing debate about their longterm safety for children [25].

\section{Limitations}

Limitations of this brief report are that only two-year data for four patients with OI VI were available, a consequence of the fact that OI VI is extremely rare, with only a few patients currently known in Germany. This small sample size limits the conclusions that can be drawn from our data. No controlled setting is available to compare the presented effects with bisphosphonate efficacy. Recently, several case reports about the short-time use of denosumab in children with different conditions became available, but there are no long-term data on the use in children [21-23,26].

Even though this report underlines that denosumab is well tolerated, the treatment period of two years is still too short to predict that it will be safe also in the longterm course, as e.g. allergic reactions or antibodies targeting denosumab may require time to develop. The patients have to be monitored longer in order to evaluate the risk-benefit ratio more precisely.

In conclusion, medium-term treatment with denosumab seems to be safe. No severe side effects were seen, and no growth arrest was observed in the presented patients. Efficacy seems to be superior to earlier bisphosphonate treatment. Treatment with denosumab led to an increase of areal bone mineral density and mobility, as well as to a marked and reversible suppression of bone resorption. Further controlled trials are needed to assess the longterm effects in comparison to bisphosphonate treatment prospectively. Last but not least this report is a striking example of the fact that a precise molecular diagnosis can have immediate implications for the therapeutic regime, and that the period of time required to transfer new scientific insights from "bench to bedside" can sometimes be very short - in this case, less than a year.

\section{Informed consent}

All procedures followed were in accordance with the ethical standards of the responsible committee on human experimentation (institutional and national) and with the Helsinki Declaration of 1975, as revised in 2000. Informed consent was obtained from all patients/parents for being included in the study.

\section{Competing interests}

$\mathrm{CN}$ and FK state that they have no conflicts of interest. HHK and OS state that they worked as consultancies without honoraria for AMGEN. ES states that he got speakers fee from AMGEN.

\section{Authors' contributions}

HHK and OS drafted the manuscript and evaluated the biochemical markers and the mobility assessments. HHK, OS and ES treated the patients and designed the therapeutic approach. CN performed the molecular analysis and provided the pathophysiological background for the treatment. FK, HHK and OS evaluated the x-ray and bone density measurements. All authors read and approved the final manuscript.

\section{Acknowledgements}

The authors would like to express their gratitude to the families who contributed to this report. OS ES and HHK were involved in the treatment of the patients. Additionally, HHK drafted the manuscript. HHK analyzed with FK and OS the radiograms, CN, OS and ES reviewed the manuscript and worked out the diagnosis clinically and genetically. All authors finally approved the manuscript.

\section{Author details}

'Children's Hospital, University of Cologne, Kerpenerstr. 62, D-50931 Cologne, Germany. ${ }^{2}$ Institute of Human Genetics, University of Cologne, Cologne, Germany. ${ }^{3}$ Institute for Radiology, University of Cologne, Cologne, Germany.

Received: 12 June 2014 Accepted: 8 September 2014

Published online: 26 September 2014

\section{References}

1. Rauch F, Glorieux FH: Osteogenesis imperfecta. Lancet 2004, 363:1377-1385.

2. Glorieux FH, Bishop NJ, Plotkin H, Chabot G, Lanoue G, Travers R: Cyclic administration of pamidronate in children with severe osteogenesis imperfecta. N Engl J Med 1998, 339:947-952.

3. Gatti D, Antoniazzi F, Prizzi R, Braga V, Rossini M, Tato L, Viapiana O, Adami S: Intravenous neridronate in children with osteogenesis imperfecta: a randomized controlled study. J Bone Miner Res 2005, 20:758-763.

4. Glorieux FH, Ward LM, Rauch F, Lalic L, Roughley PJ, Travers R: Osteogenesis imperfecta type Vl: a form of brittle bone disease with a mineralization defect. J Bone Miner Res 2002, 17:30-38.

5. Land C, Rauch F, Travers R, Glorieux FH: Osteogenesis imperfecta type VI in childhood and adolescence: effects of cyclical intravenous pamidronate treatment. Bone 2007, 40:638-644.

6. Becker J, Semler O, Gilissen C, Li Y, Bolz HJ, Giunta C, Bergmann C, Rohrbach M, Koerber F, Zimmermann K, de Vries P, Wirth B, Schoenau E, Wollnik B, Veltman JA, Hoischen A, Netzer C: Exome sequencing identifies truncating mutations in human SERPINF1 in autosomal-recessive osteogenesis imperfecta. Am J Hum Genet 2011, 88:362-371.

7. Homan EP, Rauch F, Grafe I, Lietman C, Doll JA, Dawson B, Bertin T, Napierala D, Morello R, Gibbs R, White L, Miki R, Cohn DH, Crawford S, 
Travers R, Glorieux FH, Lee B: Mutations in SERPINF1 cause Osteogenesis imperfecta Type VI. J Bone Miner Res 2011, 26:2798-2803.

8. Rauch F, Husseini A, Roughley P, Glorieux FH, Moffatt P: Lack of circulating pigment epithelium-derived factor is a marker of osteogenesis imperfecta type VI. J Clin Endocrinol Metab 2012, 97:E1550-1556.

9. Akiyama T, Dass CR, Shinoda Y, Kawano H, Tanaka S, Choong PF: PEDF regulates osteoclasts via osteoprotegerin and RANKL. Biochem Biophys Res Commun 2009, 391:789-794.

10. Cummings SR, San Martin J, McClung MR, Siris ES, Eastell R, Reid IR, Delmas P, Zoog HB, Austin M, Wang A, Kutilek S, Adami S, Zanchetta J, Libanati C, Siddhanti S, Christiansen C: Denosumab for prevention of fractures in postmenopausal women with osteoporosis. N Engl J Med 2009, 361:756-765.

11. Chawla S, Henshaw R, Seeger L, Choy E, Blay JY, Ferrari S, Kroep J, Grimer R, Reichardt P, Rutkowski P, Schuetze S, Skubitz K, Staddon A, Thomas D, Qian Y, Jacobs I: Safety and efficacy of denosumab for adults and skeletally mature adolescents with giant cell tumour of bone: interim analysis of an open-label, parallel-group, phase 2 study. Lancet Oncol 2013, 14:901-908.

12. Semler O, Netzer C, Hoyer-Kuhn H, Becker J, Eysel P, Schoenau E: First use of the RANKL antibody denosumab in Osteogenesis Imperfecta Type VI. J Musculoskelet Neuronal Interact 2012, 12:183-188.

13. McClung MR, Lewiecki EM, Cohen SB, Bolognese MA, Woodson GC, Moffett AH, Peacock M, Miller PD, Lederman SN, Chesnut CH, Lain D, Kivitz AJ, Holloway DL, Zhang C, Peterson MC, Bekker PJ: Denosumab in postmenopausal women with low bone mineral density. $N$ Engl J Med 2006, 354:821-831.

14. Wacker W, Barden H: Pediatric Reference Data for Male and Female Total Body and Spine BMD and BMC. Dallas, TX: Presented at: International Society of Clinical Densitometry; 2011.

15. Rauch F, Georg M, Stabrey A, Neu C, Blum WF, Remer T, Manz F, Schoenau E: Collagen markers deoxypyridinoline and hydroxylysine glycosides: pediatric reference data and use for growth prediction in growth hormone-deficient children. Clin Chem 2002, 48:315-322.

16. Koerber F, Schulze Uphoff U, Koerber S, Schonau E, Maintz D, Semler O: Introduction of a new standardized assessment score of spine morphology in osteogenesis imperfecta. Rofo 2012, 184:719-725.

17. Semler O, Beccard R, Palmisano D, Demant A, Fricke O, Schoenau E, Koerber $F$ : Reshaping of vertebrae during treatment with neridronate or pamidronate in children with osteogenesis imperfecta. Horm Res Paediatr 2011, 76:321-327.

18. Russell DJ, Rosenbaum PL, Cadman DT, Gowland C, Hardy S, Jarvis S: The gross motor function measure: a means to evaluate the effects of physical therapy. Dev Med Child Neurol 1989, 31:341-352.

19. Cintas HL, Siegel KL, Furst GP, Gerber LH: Brief assessment of motor function: reliability and concurrent validity of the Gross Motor Scale. Am J Phys Med Rehabil 2003, 82:33-41.

20. Kendler DL, Roux C, Benhamou CL, Brown JP, Lillestol M, Siddhanti S, Man HS, San Martin J, Bone HG: Effects of denosumab on bone mineral density and bone turnover in postmenopausal women transitioning from alendronate therapy. J Bone Miner Res 2010, 25:72-81.

21. Shroff R, Beringer O, Rao K, Hofbauer LC, Schulz A: Denosumab for post-transplantation hypercalcemia in osteopetrosis. N Engl J Med 2012, 367:1766-1767.

22. Grasemann C, Schundeln MM, Hovel M, Schweiger B, Bergmann C, Herrmann R, Wieczorek D, Zabel B, Wieland R, Hauffa BP: Effects of RANKligand antibody (denosumab) treatment on bone turnover markers in a girl with juvenile Paget's disease. J Clin Endocrinol Metab 2013, 98:3121-3126.

23. Boyce A, Chong W, Yao J, Gafni R, Kelly M, Chamberlain C, Bassim C, Cherman N, Ellsworth M, Kasa-Vubu J, Farley F, Molinolo A, Bhattacharyya N, Collins M: Denosumab treatment for fibrous dysplasia. J Bone Miner Res 2012, 27:1462-1470.
24. Bekker PJ, Holloway DL, Rasmussen AS, Murphy R, Martin SW, Leese PT, Holmes GB, Dunstan CR, DePaoli AM: A single-dose placebo-controlled study of AMG 162, a fully human monoclonal antibody to RANKL, in postmenopausal women. J Bone Miner Res 2004, 19:1059-1066.

25. Whyte MP, Wenkert D, Clements KL, McAlister WH, Mumm S: Bisphosphonate-induced osteopetrosis. N Engl J Med 2003, 349:457-463.

26. Karras NA, Polgreen LE, Ogilvie C, Manivel JC, Skubitz KM, Lipsitz E: Denosumab treatment of metastatic giant-cell tumor of bone in a 10-year-old girl. J Clin Oncol 2013, 31:e200-202.

doi:10.1186/s13023-014-0145-1

Cite this article as: Hoyer-Kuhn et al:: Two years' experience with denosumab for children with Osteogenesis imperfecta type Vl. Orphanet Journal of Rare Diseases 2014 9:145.

\section{Submit your next manuscript to BioMed Central and take full advantage of:}

- Convenient online submission

- Thorough peer review

- No space constraints or color figure charges

- Immediate publication on acceptance

- Inclusion in PubMed, CAS, Scopus and Google Scholar

- Research which is freely available for redistribution

Submit your manuscript at www.biomedcentral.com/submit
C Biomed Central 